\title{
The role of autophagy induced by pemetrexed in lung adenocarcinoma cells
}

\author{
JI-HYE PARK ${ }^{1 *}$, YOUNG-RAE LEE ${ }^{2,3 *}$, HONG-SEOB SO ${ }^{3}$, KANG-KYOO LEE $^{4}$, SAM-YOUN LEE $^{5}$, \\ SUN-ROCK MOON ${ }^{4}$, HYANG-JEONG JO ${ }^{6}$, SEOUL LEE ${ }^{7}$, KYUYONG JEONG $^{7}$, \\ KANG-BEOM KWON ${ }^{3}$ and SEI-HOON YANG ${ }^{1}$ \\ ${ }^{1}$ Department of Internal Medicine, Wonkwang University School of Medicine; ${ }^{2}$ Department of Oral Biochemistry \\ and Institute of Biomaterials Implant, School of Dentistry, Wonkwang University; ${ }^{3}$ Center for Metabolic \\ Function Regulation, Wonkwang University School of Medicine; Departments of ${ }^{4}$ Radiation Oncology and \\ ${ }^{5}$ Thoracic and Cardiovascular Surgery, Wonkwang University School of Medicine; ${ }^{6}$ Department of Pathology, \\ Gunsan Wonkwang University Hospital, Wonkwang University School of Medicine; ${ }^{7}$ Department of \\ Pharmacology, Wonkwang University School of Medicine, Iksan 570-749, Republic of Korea
}

Received December 12, 2013; Accepted January 10, 2014

DOI: 10.3892/or.2014.3071

\begin{abstract}
Autophagy is known as an important regulatory mediator for cell survival or death and its important role in cancer. Pemetrexed (PTX) has been used in chemotherapy for lung cancer. However, the underlying molecular mechanisms have not been fully clarified. To investigate the role of autophagy induced by PTX in A549 cells, we performed MTT assay, acridine orange staining, western blotting, Annexin V/ PI by using the 3-MA autophagy inhibitor. PTX induced autophagy after $48 \mathrm{~h}$ treatment in A549 cells. Furthermore, PTX showed acidic vesicular organelles (AVOs) and expressed LC3-II in A549 cells. The induction of autophagy by PTX was inhibited by 3-MA which was confirmed by reduced AVOs. When the autophagy was inhibited, Annexin V was increased. In addition, PARP cleavage was increased as shown by western blotting. Taken together, PTX induced autophagy in A549 cells and these cellular events possibly cause the apoptotic and/or necrotic cell death of A549 cells.
\end{abstract}

\section{Introduction}

Lung cancer is considered a major cause of cancer-related mortality worldwide. The incidence of lung cancer has

Correspondence to: Professor Sei-Hoon Yang, Department of Internal Medicine, Wonkwang University School of Medicine, Iksan 570-749, Republic of Korea

E-mail: yshpul@wku.ac.kr

Professor Kang-Beom Kwon, Center for Metabolic Function Regulation, Wonkwang University School of Medicine, Iksan 570-749, Republic of Korea

E-mail: desson@wku.ac.kr

*Contributed equally

Key words: pemetrexed, autophagy, lung cancer, 3-MA increased by $51 \%$ since 1985 . Lung cancer is clinically classified into two types: small cell lung carcinoma (SCLC) and non-small cell lung carcinoma (NSCLC). SCLC is known as a type of highly malignant cancer and corresponds to $20 \%$ of all lung cancer cases; NSCLC represents approximately $80 \%$ of all cases. It is clinically considered that NSCLC is relatively insensitive to chemotherapy compared with small cell carcinoma $(1,2)$. Although several treatments including chemoradiation and combination treatment have been developed to treat patients with lung cancer, the survival rates of lung cancer patients remain very low $(1,3,4)$.

It has recently been considered that autophagy is a physiological process for the temporary survival of cells, and cellular stresses such as oxidative stress, nutrient starvation, misfolded protein accumulation and chemotherapy can induce autophagy $(5,6)$. At the beginning of the processes related with the autophagy induction, autophagosomes are formed by elongation of double-membrane, and they sequester cellular components such as damaged proteins and/or organelles. Autophagosomes are then merged with lysosome to autolysosome formation, which produces the degradation of organelles in the cells $(7,8)$.

Chemotherapy is a very important option for the treatment of various types of cancer, including lung cancer. Pemetrexed (PTX) is one of the most popular chemotherapies currently used for cancer patients. PTX is a multi-targeted antifolate cytotoxic agent and has been widely used as a single or combination chemotherapy agent with platinum compounds such as cisplatin for the treatment of patients with NSCLC $(4,9)$. Several studies have reported the cellular and molecular roles of PTX in the regulation of apoptosis, cell cycle arrest and DNA synthesis (10-12). It is known that PTX induces apoptosis through inhibiting cellular enzymes responsible for the synthesis of pyrimidine and purine, and they mainly indicate the thymidylate synthase, glycinamide ribonucleotide formyl transferase and dihydrofolate reductase $(13,14)$. 
In addition to the apoptotic property of PTX, recent studies have focused on the molecular property of PTX to induce autophagy, since apoptotic processes may not fully explain the chemotherapeutic values of PTX, and PTX revealed several limitations to the application in clinical study (15). Therefore, to date, the cellular mechanisms involved in the PTX-induced death of NSCLC are not fully understood.

Based on previous knowledge and information, we hypothesized that PTX may accelerate the autophagy induction in the lung adenocarcinoma cells of humans, and these cellular events possibly regulate the chemotherapeutic effects of PTX through induction of apoptotic and/or necrotic cell death. To examine this hypothesis, the present study investigated whether PTX concurrently induces autophagy and apoptosis in the cultured A549 lung adenocarcinoma cells.

\section{Materials and methods}

Cell line. A549 cells were purchased from the American Type Culture Collection (ATCC). A549 cells were cultured with RPMI-1640 medium supplemented with $10 \%$ fetal bovine serum (FBS), $1 \%$ antibiotics and $10 \mathrm{mM}$ HEPES. The cells were incubated in $95 \% \mathrm{O}_{2} / 5 \% \mathrm{CO}_{2}$ at $37^{\circ} \mathrm{C}$. The medium was replaced every $24 \mathrm{~h}$. All experiments were conducted under conditions of cells in the log phase.

Reagents. RPMI-1640, penicillin/streptomycin, trypsin, FBS and HEPES were obtained from Gibco-BRL (Grand Island, NY, USA). The culture plates were purchased from Nunc (Thermo Fisher Scientific, Roskilde, Denmark). PTX was obtained from Eli Lilly Ltd. Propidium iodide (PI), 3-methyladenine (3-MA), 3-(4,5-dimethylthiazol-2-yl)-2,5-diphenyltetrazolium bromide (MTT) and acridine orange (AO) were purchased from SigmaAldrich Chemicals (St. Louis, MO, USA). Poly(ADP-ribose) polymerase-1/2 (PARP1/2) and glyceraldehyde 3-phosphate dehydrogenase (GAPDH) antibodies were obtained from Santa Cruz Biotechnology, Inc. (Santa Cruz, CA, USA). The LC3 antibody was obtained from Cell Signaling (Boston, MA, USA). The secondary antibody was obtained from Amersham (Buckinghamshire, UK), and the polyvinylidine fluoride (PVDF) membranes and the enhanced chemiluminescent (ECL) kits were purchased from Millipore Co. (Billerica, MA, USA).

Measurement of cell viability. The cell viability was determined by MTT assay. A549 cells were seeded in 24-well plates at a density of $1 \times 10^{4}$ cells and incubated for $24 \mathrm{~h}$. After treatment with PTX $(0.5,1.0$ and $1.5 \mu \mathrm{M})$ in the presence or absence of 3-MA $(10 \mathrm{mM})$, assay reagent $(5 \mathrm{mg} / \mathrm{ml})$ was added to each well and plates were incubated in $5 \% \mathrm{CO}_{2}$ at $37^{\circ} \mathrm{C}$ for $4 \mathrm{~h}$. Crystals were dissolved in $200 \mu \mathrm{l}$ of $99.0 \%$ dimethyl sulfoxide (DMSO). To measure cell death, the absorbance was spectrophotometrically measured at $570 \mathrm{~nm}$ with a microplate ELISA reader (Thermo Scientific). The absorbance of PTX-treated cells was expressed as percentage of the absorbance produced by control cells.

Immunoblotting assay. The cells were then pretreated with $10 \mathrm{mM}$ of 3 -MA for $1 \mathrm{~h}$, and PTX $(0.5 \mu \mathrm{M})$ were then subsequently added to the 60 -mm culture dishes, followed by incubation for $48 \mathrm{~h}$. Subsequently, the cells were harvested and washed twice with ice-cold PBS and lysed in lysis buffers (50 mM HEPES, $150 \mathrm{mM} \mathrm{NaCl}, 1 \%$ deoxycholate, $1 \mathrm{mM}$ EDTA, $1 \mathrm{mM}$ PMSF and $1 \mu \mathrm{g} / \mathrm{ml}$ aprotinin, $\mathrm{pH}$ 7.4). Following incubation of samples for $1 \mathrm{~h}$ on ice, the cells were centrifuged at $10,000 \mathrm{rpm}$ for $30 \mathrm{~min}$ at $4^{\circ} \mathrm{C}$, and the supernatants were carefully collected. The protein concentration of supernatants was determined using the Bradford method. For western blot analysis, equal amounts of total proteins were loaded onto each well of 10 or $15 \%$ sodium dodecyl sulfate-polyacrylamide gel electrophoresis (SDS-PAGE), and then transferred onto PVDF membranes. The PVDF membranes were blocked with 5\% skimmed milk in PBS for 90 min and briefly washed in PBS. The immunoblots were analyzed using specific antibodies recognizing LC3 and PARP proteins. The membrane was then washed with PBS and treated with secondary antibodies for $1 \mathrm{~h}$. Proteins were then visualized using an ECL kit.

Analysis of apoptosis. For the quantitative analysis of cellular apoptosis, the cells were inoculated in 6-well plates and incubated for $24 \mathrm{~h}$. The cells were pretreated with $10 \mathrm{mM}$ of 3-MA for $1 \mathrm{~h}$, and PTX at $0.5 \mu \mathrm{M}$ was then added, followed by incubation for $48 \mathrm{~h}$. After completion of treatment, the cells were harvested using $0.25 \%$ trypsin and then washed twice in PBS. They were subsequently treated with Annexin V/fluorescein isothiocyanate (FITC; $0.5 \mu \mathrm{g} / \mathrm{ml}$ at final concentration), PI $(2 \mu \mathrm{g} / \mathrm{ml}$ at final concentration) and apoptosis detection kit for $10 \mathrm{~min}$ at room temperature. The cells were then immediately examined using a flow cytometer (FACSVantage Flow Cytometer, Becton-Dickinson Immunocytometry System; San Jose, CA, USA) after addition of $250 \mu 1$ of binding buffer. Analysis was performed using CellQuest software (BectonDickinson, Franklin Lakes, NJ, USA).

Analysis of autophagy. Quantitative analysis of autophagy was performed by staining the cells with $\mathrm{AO}$ and using flow cytometry as previously described (16). The cells were grown in 6-well plates and incubated for $24 \mathrm{~h}$. After reaching the log phase, the cells were pretreated with $10 \mathrm{mM}$ of 3-MA for $1 \mathrm{~h}$, and PTX at $0.5 \mu \mathrm{M}$ was subsequently added, followed by incubation for $48 \mathrm{~h}$. After completion of treatment, the cells were stained with $\mathrm{AO}(1 \mu \mathrm{g} / \mathrm{ml})$ for $15 \mathrm{~min}$ at $37^{\circ} \mathrm{C}$ and harvested with trypsin $(0.25 \%)$, followed by washing in PBS. The samples were then combined with $500 \mu \mathrm{l}$ of FACS buffer (1\% FBS in PBS). The cells were immediately counted using FACS system, and then analysis was performed using CellQuest software.

Statistical analysis. All experiments were conducted in triplicate, and results are expressed as the means \pm SEM. One-way analysis of variance (ANOVA) was used to compare data between groups. When a statistically significant difference was encountered, post hoc test confirmed Tukey's multiple comparison test. Significance was set at $\mathrm{p}<0.05$. The GraphPad Prism 4.0 (GraphPad Software, San Diego, CA, USA) was used for statistical analysis.

\section{Results}

PTX-induced autophagy in A549 cells. Firstly, MTT assay was performed to measure the changes of cell viability by treatment 

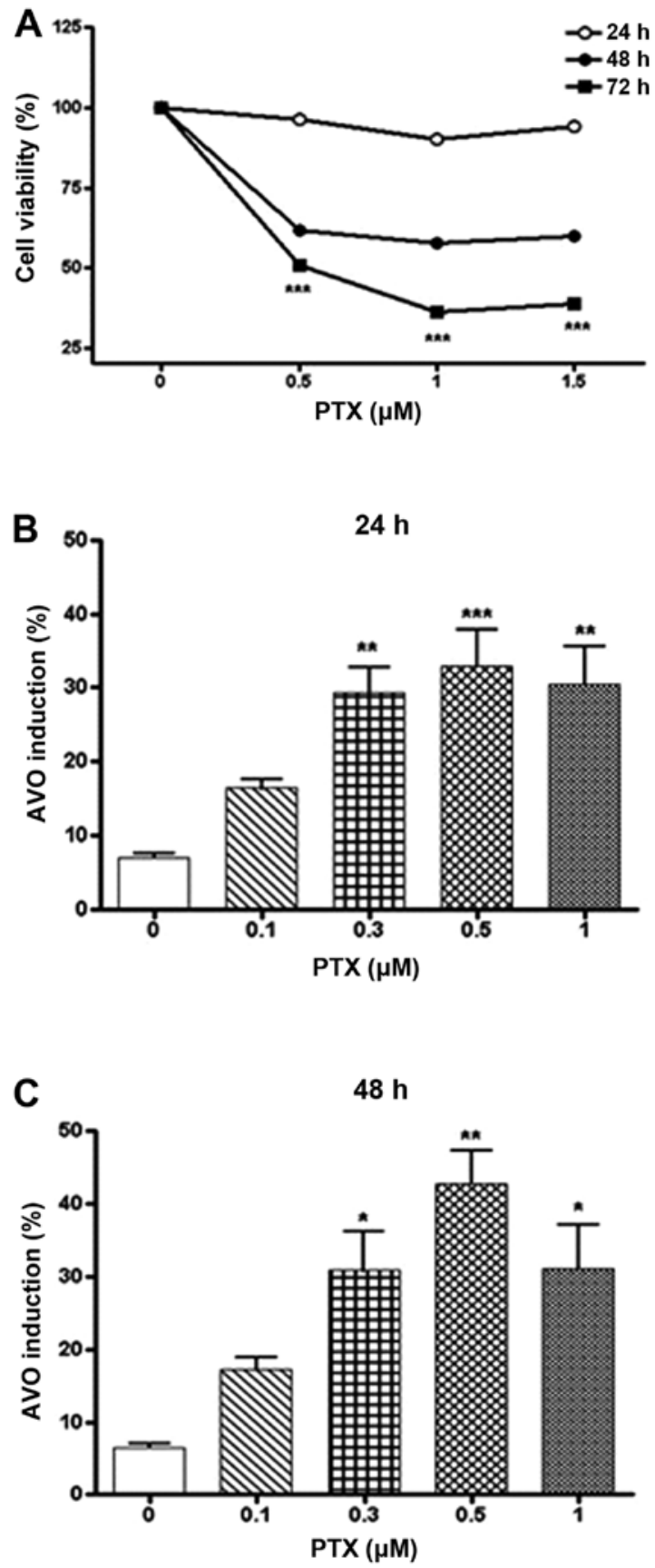

Figure 1. Effects of pemetrexed (PTX) on the cell viability and autophagy in cultured A549 cells. The cells were seeded at a density of $1 \times 10^{4}$ cells/well in 24-well flat-bottomed plates and incubated at $37^{\circ} \mathrm{C}$ for $24 \mathrm{~h}$. After treatment of PTX $(0.5-1.5 \mu \mathrm{M})$ for 24,48 and $72 \mathrm{~h}$, the cell viability was measured by (A) MTT assay. A549 cells were seeded at a density of $1 \times 10^{5}$ cells/well in 6 -well flat-bottomed plates and incubated at $37^{\circ} \mathrm{C}$ for $24 \mathrm{~h}$. After treatment of the cells with PTX (0.1-1.0 $\mu \mathrm{M})$ for (B) 24 and (C) $48 \mathrm{~h}$, acridine orange-positive cells were measured by FACS. ${ }^{*} \mathrm{p}<0.05,{ }^{* *} \mathrm{p}<0.01$ and ${ }^{* * *} \mathrm{p}<0.001$ vs. control cells.

of PTX. As shown in Fig. 1A, when A549 cells were incubated with $\operatorname{PTX}(0.5-1.5 \mu \mathrm{M})$ for 24-72 $\mathrm{h}$, the cell viability decreased in a dose- and time-dependent manner. Incubation of A549 cells with PTX for 24 and $48 \mathrm{~h}$ did not significantly affect the cell viability, whereas all concentrations of PTX examined in this study significantly decreased the cell viability by incubation for $72 \mathrm{~h}$. Next, the present study investigated whether PTX induces autophagy in A549 cells. To examine this hypothesis,

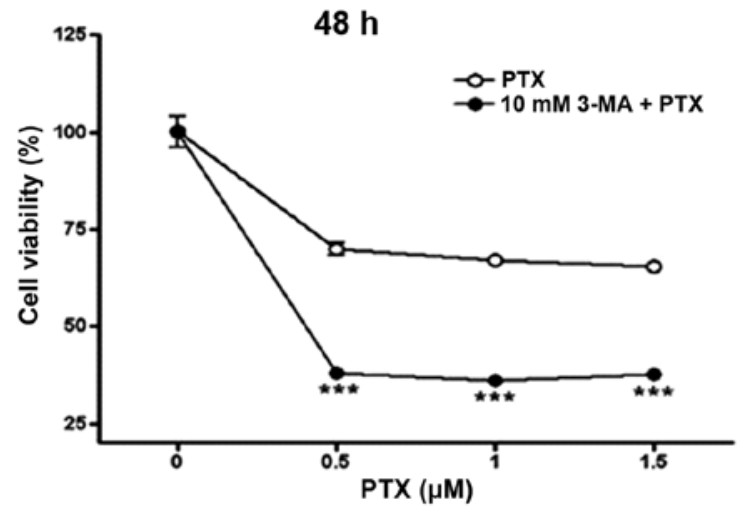

Figure 2. Effects of 3-MA on the cell viability changed by pemetrexed (PTX) treatment in cultured lung adenocarcinoma cells. A549 cells were seeded at $1 \times 10^{4}$ cells/well in 24 -well flat-bottomed plates and incubated at $37^{\circ} \mathrm{C}$ for $24 \mathrm{~h}$. The cells were pretreated with $10 \mathrm{mM}$ of 3-MA for $1 \mathrm{~h}$ and subsequently treated with PTX $(0.5-1.5 \mu \mathrm{M})$ for $48 \mathrm{~h}$. The cell viability was then measured by MTT assay. The cell viability of the untreated cells was regarded as $100 \%$. **** $\mathrm{p}<0.001$ vs. control cells.

the cells were treated with PTX $(0.1-1.0 \mu \mathrm{M})$ for 24 and $48 \mathrm{~h}$ and stained with $\mathrm{AO}$ to detect the formation of acidic vesicular organelles (AVOs). As shown in Fig. 1B and C, PTX produced the formation of AVOs in a dose-dependent manner, and a maximal effect of PTX was observed at a concentration of $0.5 \mu \mathrm{M}$. When A549 cells were incubated with $0.5 \mu \mathrm{M}$ of PTX for 24 and $48 \mathrm{~h}$, the formation of AVOs was found to be 32.9 and $52.7 \%$, respectively. Based on these results, the following studies employed the concentration of $0.5 \mu \mathrm{M}$ of PTX and the 48-h incubation period.

Effects of 3-MA on the PTX-induced cell death. To investigate whether autophagy regulates the cell death caused by PTX, A549 cells were incubated with PTX in the presence or absence of $10 \mathrm{mM} 3-\mathrm{MA}$, an autophagy inhibitor, for $48 \mathrm{~h}$, and the obtained results are shown in Fig. 2. Consistent with the results shown in Fig. 1A, the cell viability was significantly reduced by treatment of PTX $(0.5-1.5 \mu \mathrm{M})$ for $48 \mathrm{~h}$. Of note, treatment of A549 cells with $10 \mathrm{mM}$ of 3-MA significantly accelerated the reduction of cell viability induced by PTX. These results clearly indicate that autophagy is implicated in the PTX-induced death of lung adenocarcinoma cells.

Effects of 3-MA on the PTX-induced autophagy induction. To confirm the results shown in Fig. 2, we then performed the AO stain to estimate the 3-MA-induced variation of autophagy, and the obtained results are shown in Fig. 3A. The rates of AO-positive cells in none-treated cells were found to be $6.1 \%$ of total cells, and these rates were significantly increased by treatment of PTX $(0.5 \mu \mathrm{M})$ to $43.9 \%$. Notably, the PTX-induced increase of AO-positive cells was markedly attenuated by co-treatment of 3-MA $(10 \mathrm{mM})$, and its rate was revealed as $13.2 \%$ of total cells.

Additionally, the present study further examined the inhibitory effects of 3-MA on the PTX-induced autophagy induction by measuring the expression of LC3-II which is widely accepted as an autophagy marker, and the obtained results are shown in Fig. 3B. PTX at $0.5 \mu \mathrm{M}$ clearly elevated the expression of LC3-II in cultured A549 cells, and this increment was mark- 

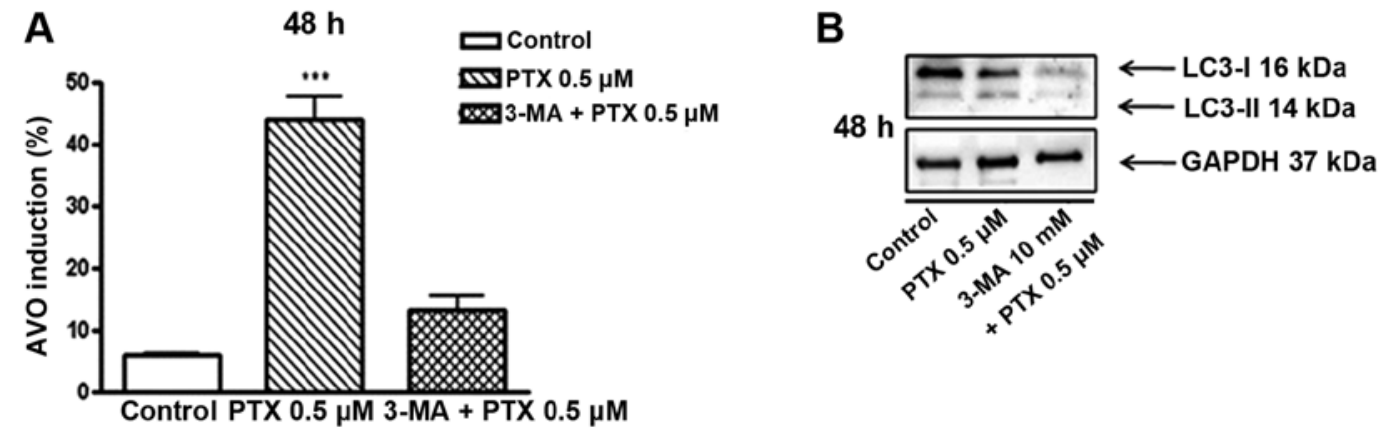

Figure 3. Effects of 3-MA on the (A) autophagy induction and (B) LC3 expression caused by pemetrexed (PTX) in cultured lung adenocarcinoma cells. A549 cells were seeded at $1 \times 10^{5}$ cells/well in 6 -cm dishes and incubated at $37^{\circ} \mathrm{C}$ for $24 \mathrm{~h}$. The cells were then pretreated with $10 \mathrm{mM}$ of 3-MA for $1 \mathrm{~h}$, and PTX $(0.5 \mathrm{mM})$ was then added to the culture dishes, followed by incubation for $48 \mathrm{~h}$. After completion of treatment, the autophagy-positive cells were detected by acridine orange stain and flow cytometry, and LC3 expression was measured by western blot analysis. GAPDH was used as an internal standard for each experiment. ${ }^{* * *} \mathrm{p}<0.001$ vs. control cells.
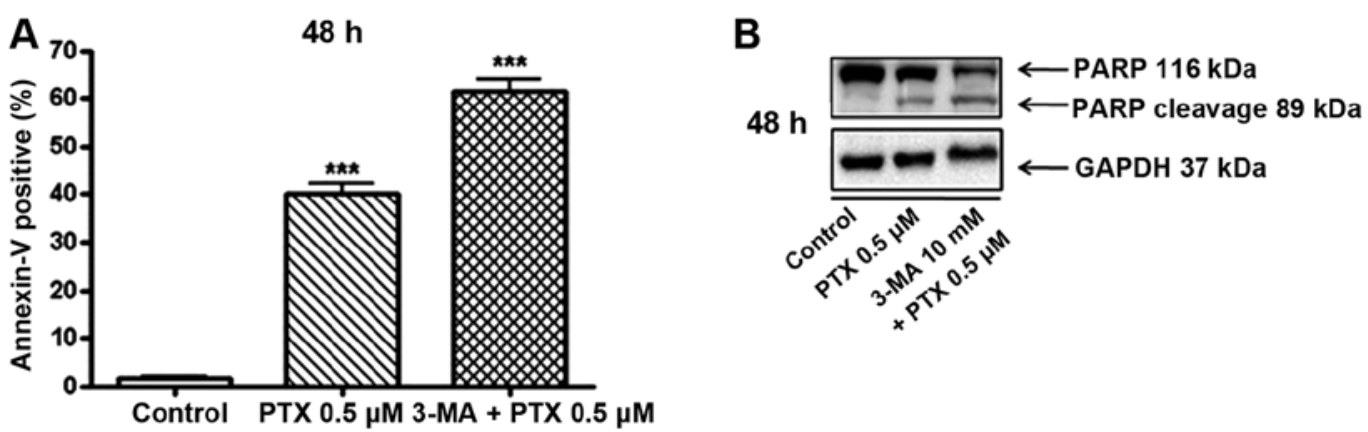

Figure 4. Effects of 3-MA on the (A) Annexin V-positivity and (B) PARP cleavage caused by pemetrexed (PTX) in cultured lung adenocarcinoma cells. A549 cells were seeded at $1 \times 10^{5}$ cells/well in $6-\mathrm{cm}$ dishes and incubated at $37^{\circ} \mathrm{C}$ for $24 \mathrm{~h}$. The cells were pretreated with $10 \mathrm{mM}$ of $3-\mathrm{MA}$ for $1 \mathrm{~h}$, and PTX at $0.5 \mu \mathrm{M}$ was then added followed by incubation for $48 \mathrm{~h}$. After completion of treatment, the apoptotic cells were stained with Annexin V/PI and analyzed by flow cytometry, and PARP cleavage was measured by western blot analysis. GAPDH was used as an internal standard for each experiment. ${ }^{* * *}$ p $<0.001$ vs. control cells.

edly reduced by co-treatment of 3-MA (10 mM). These results clearly suggest that autophagy is involved in the death of lung adenocarcinoma cells caused by PTX.

Effects of 3-MA on the PTX-induced apoptosis. Furthermore, to confirm the results shown in Fig. 2, that PTX-induced death of cultured lung adenocarcinoma cells is increased by inhibiting the autophagy induction, and to clarify the type of cell death, the present study performed Annexin V/PI analysis, and the obtained results are shown in Fig. 4A. When A549 cells were cultured with $0.5 \mu \mathrm{M}$ of PTX for $48 \mathrm{~h}$, Annexin V-positive apoptotic cells were increased to $38.4 \%$ compared to those of control cells. Importantly, 3-MA at $10 \mathrm{mM}$ further elevated the PTX-induced increase of Annexin V-positive cells to 59.7\% in comparison with control cells. In addition to the results showing Annexin V-positive cells, the present study examined the PARP expression using western blot analysis, and the obtained results are shown in Fig. 4B. When A549 cells were incubated with PTX $(0.5 \mu \mathrm{M})$ for $48 \mathrm{~h}$, in comparison with control, expression of the cleaved PARP was markedly increased. These cleavages of PARP by PTX treatment were accelerated by co-treatment of 3-MA $(10 \mathrm{mM})$. These results may indicate that inhibition of autophagy formation promotes the apoptotic pathways in cultured human lung adenocarcinoma cells.

\section{Discussion}

Although pemetrexed (PTX) is one of the most popular chemotherapies for treating patients with lung cancer, its pharmacotherapeutical mechanisms responsible for the anticancer activity are not completely understood. Therefore, using A549 cells, the present study investigated the hypothesis that PTX may accelerate the autophagy formation in A549 cells, and these cellular events possibly mediate the chemotherapeutic effects of PTX through induction of apoptotic and/or necrotic cell death. PTX caused a significant reduction in the viability of cultured A549 lung adenocarcinoma cells, whereas it significantly increased the autophagy induction. The maximal concentration of PTX to induce autophagy formation was revealed to be $0.5 \mu \mathrm{M}$. An autophagy inhibitor, 3-MA, accelerated the decrease in the cell viability induced by PTX, and inhibition of autophagy induction promoted the apoptotic cell death which were demonstrated by expressional changes of LC3 and PARP in cultured A549 cells. These results likely indicate the cellular and molecular mechanisms involved in the chemotherapeutic activity of PTX to be used for treating human lung adenocarcinoma.

Lung cancer in humans has shown little improvement in survival rates over the past 30 years and the therapeutic effects of radiotherapy and chemotherapy remain unsatisfactory (1). 
It is known that human lung cancer is clinically classified into small cell lung carcinoma (SCLC) and non-small cell lung carcinoma (NSCLC), and NSCLC constitutes $\sim 80 \%$ of lung cancer cases. PTX has generally been used as a single agent or first-line chemotherapy in combination with platinum agents in the treatment of the advanced NSCLC (17-19). However, it is clinically considered that PTX often induces specific sideeffects such as myelotoxicity and macular skin rash, and this drug also has a limited therapeutic window and drug resistance with regard to pharmacokinetical and pharmacodynamical aspects (15).

Accumulating evidence suggests that PTX induces autophagy (20), and autophagy is a cellular self-catabolic process to enhance the cell survival under certain conditions such as oxidative stress, chemotherapy agent and starvation $(5,6)$. Autophagy is also known to play an important role in the development and progression of tumors. For example, autophagy is predominantly observed in the incipient stage of tumor development and also maintains cell survival from the several different types of stresses including tumor progression and chemotherapy to treat the already formed tumor $(21,22)$. However, the cellular pathophysiological roles of autophagy in the development and/or progression of human cancer remain controversial. Most evidence indicates the roles of autophagy in supporting the cell survival property. In contrast to these suggestions, it has also been reported that autophagy contributes to cell death resulting from progression self-consumption $(23,24)$. However, the cellular properties of autophagy have not yet been fully confirmed, and several questions regarding pharmacotherapeutical pathways of PTX remain to be elucidated.

The present study investigated whether PTX induces autophagy in the cultured A549 human lung adenocarcinoma cells, and examined the pathophysiological and cellular roles of autophagy in the lung adenocarcinoma cells treated with PTX. Our results confirmed that PTX induces autophagy in a dose- and time-dependent manner, and the autophagy induced by PTX is likely involved in the regulation of survival of lung adenocarcinoma cells. Here, the pharmacological strategy was employed to evaluate the pathophysiological relationship between autophagy and apoptosis and the 3-MA autophagy inhibitor was used. This drug disturbs the autophagy progression by inhibiting class III phosphoinositide 3-kinase (PI3K), which is essential for the autophagosome formation in the isolated membrane or phagophore $(25,26)$. Several studies have suggested that autophagy inhibition increases the antitumor effects of chemotherapy through targeting apoptotic pathways $(27,28)$. Similar findings to the previous suggestions were also observed in this study, indicating that compared with PTX alone, combination of PTX with 3-MA attenuates the survival of the cultured A549 cells. Therefore, it is conceivable that autophagy inhibition by 3-MA augments the autophagy formation caused by PTX through regulation of PI3K signaling pathways, and these phenomena possibly indicate the pharmacotherapeutical values of combination therapy of PTX with 3-MA to treat human lung adenocarcinoma.

In the present study, we also observed that autophagy is critically related to the apoptotic cell death with regard to cell signaling. Therefore, this study investigated the expressional changes of signaling proteins, which are known as a mediator for the modulation of the autophagy and apoptotic pathways. It is known that LC3 forms the double membranes of autophagosome, and this protein is then generally considered as a useful marker to demonstrate the induction and/or formation of autophagy. Also, AO can be used as a marker to detect autophagy. As expected in the working hypothesis, 3-MA significantly reduced the LC3-II expression and AVO formation in cultured A549 cells. These results clearly indicate that the experimental method used in this study may be sufficient to demonstrate the autophagy induction and apoptotic cell death, and autophagy may be affected by apoptotic cell death progress.

Additionally, it is known that Annexin V and PARP probably act as main factors for regulating the cellular apoptosis, and PARP repairs the cancer cells from DNA damage. In comparison with PTX alone, the Annexin V expression was significantly increased by co-treatment of PTX with 3-MA, and the expression of cleaved PARP was also obviously increased. These results clearly indicate that apoptotic cell death is possibly augmented by inhibition of autophagy in A549 cells.

Taken together, the results of the present study suggest the cellular and molecular mechanisms responsible for the chemotherapeutic effects of PTX in the treatment of lung adenocarcinoma in humans. PTX decreases viability of cultured A549 cells through regulation of autophagy induction and apoptotic cell death, and these effects of PTX are augmented by combination with 3-MA. Based on the results of the present study, although it is difficult to tell conclusively the pharmacotherapeutical roles of PTX in the treatment of patients with lung adenocarcinoma, the inhibition of PTX-induced autophagy seems to be a more important tumor suppressive mechanism. Therefore, this study considers that autophagy inhibition is likely a useful method to treat NSCLC, including lung adenocarcinoma of humans, and the combination chemotherapy of PTX with autophagy inhibitors may be a significant strategy for obtaining the chemotherapeutic effects in patients with advanced NSCLC.

\section{Acknowledgements}

The present study was supported by Wonkwang University in 2013.

\section{References}

1. Siegel R, Naishadham D and Jemal A: Cancer statistics, 2012. CA Cancer J Clin 62: 10-29, 2012.

2. D'Addario G, Felip E; ESMO Guidelines Working Group: Non-small-cell lung cancer: ESMO clinical recommendations for diagnosis, treatment and follow-up. Ann Oncol 20 (Suppl 4): 68-70, 2009.

3. Gkiozos I, Charpidou A and Syrigos K: Developments in the treatment of non-small cell lung cancer. Anticancer Res 27: 2823-2827, 2007.

4. Scagliotti GV, Parikh P, von Pawel J, et al: Phase III study comparing cisplatin plus gemcitabine with cisplatin plus pemetrexed in chemotherapy-naive patients with advanced-stage non-small-cell lung cancer. J Clin Oncol 26: 3543-3551, 2008.

5. Katayama M, Kawaguchi T, Berger MS and Pieper RO: DNA damaging agent-induced autophagy produces a cytoprotective adenosine triphosphate surge in malignant glioma cells. Cell Death Differ 14: 548-558, 2007. 
6. Levine B and Yuan J: Autophagy in cell death: an innocent convict? J Clin Invest 115: 2679-2688, 2005.

7. Ravikumar B, Sarkar S, Davies JE, et al: Regulation of mammalian autophagy in physiology and pathophysiology. Physiol Rev 90: 1383-1435, 2010.

8. Gozuacik D and Kimchi A: Autophagy as a cell death and tumor suppressor mechanism. Oncogene 23: 2891-2906, 2004.

9. Rollins KD and Lindley C: Pemetrexed: a multitargeted antifolate. Clin Ther 27: 1343-1382, 2005.

10. Ramirez JM, Ocio EM, San Miguel JF and Pandiella A: Pemetrexed acts as an antimyeloma agent by provoking cell cycle blockade and apoptosis. Leukemia 21: 797-804, 2007.

11. Yang TY, Chang GC, Chen KC, et al: Pemetrexed induces both intrinsic and extrinsic apoptosis through ataxia telangiectasia mutated/p53-dependent and -independent signaling pathways. Mol Carcinog 52: 183-194, 2013.

12. Tonkinson JL, Worzalla JF, Teng $\mathrm{CH}$ and Mendelsohn LG: Cell cycle modulation by a multitargeted antifolate, LY231514, increases the cytotoxicity and antitumor activity of gemcitabine in HT29 colon carcinoma. Cancer Res 59: 3671-3676, 1999.

13. McLeod HL, Cassidy J, Powrie RH, et al: Pharmacokinetic and pharmacodynamic evaluation of the glycinamide ribonucleotide formyltransferase inhibitor AG2034. Clin Cancer Res 6 : 2677-2684, 2000.

14. Shih C, Chen VJ, Gossett LS, et al: LY231514, a pyrrolo[2,3-d] pyrimidine-based antifolate that inhibits multiple folate-requiring enzymes. Cancer Res 57: 1116-1123, 1997.

15. D'Angelo SP, Kris MG, Pietanza MC, Rizvi NA and Azzoli CG: A case series of dose-limiting peripheral edema observed in patients treated with pemetrexed. J Thorac Oncol 6: 624-626, 2011.

16. Mujumdar N, Mackenzie TN, Dudeja V, et al: Triptolide induces cell death in pancreatic cancer cells by apoptotic and autophagic pathways. Gastroenterology 139: 598-608, 2010.

17. Hanna N, Shepherd FA, Fossella FV, et al: Randomized phase III trial of pemetrexed versus docetaxel in patients with non-smallcell lung cancer previously treated with chemotherapy. J Clin Oncol 22: 1589-1597, 2004
18. Ciuleanu T, Brodowicz T, Zielinski C, et al: Maintenance pemetrexed plus best supportive care versus placebo plus best supportive care for non-small-cell lung cancer: a randomised, double-blind, phase 3 study. Lancet 374: 1432-1440, 2009.

19. Vogelzang NJ, Rusthoven JJ, Symanowski J, et al: Phase III study of pemetrexed in combination with cisplatin versus cisplatin alone in patients with malignant pleural mesothelioma. J Clin Oncol 21: 2636-2644, 2003.

20. Bareford MD, Hamed HA, Tang Y, et al: Sorafenib enhances pemetrexed cytotoxicity through an autophagy-dependent mechanism in cancer cells. Autophagy 7: 1261-1262, 2011.

21. Nakai A, Yamaguchi O, Takeda T, et al: The role of autophagy in cardiomyocytes in the basal state and in response to hemodynamic stress. Nat Med 13: 619-624, 2007.

22. Kondo Y, Kanzawa T, Sawaya R and Kondo S: The role of autophagy in cancer development and response to therapy. Nat Rev Cancer 5: 726-734, 2005.

23. Baehrecke EH: Autophagy: dual roles in life and death? Nat Rev Mol Cell Biol 6: 505-510, 2005.

24. Debnath J, Baehrecke EH and Kroemer G: Does autophagy contribute to cell death? Autophagy 1: 66-74, 2005.

25. Zeng X, Overmeyer JH and Maltese WA: Functional specificity of the mammalian Beclin-Vps34 PI 3-kinase complex in macroautophagy versus endocytosis and lysosomal enzyme trafficking. J Cell Sci 119: 259-270, 2006.

26. Pattingre S, Espert L, Biard-Piechaczyk M and Codogno P: Regulation of macroautophagy by mTOR and Beclin 1 complexes. Biochimie 90: 313-323, 2008.

27. Kanematsu S, Uehara N, Miki H, et al: Autophagy inhibition enhances sulforaphane-induced apoptosis in human breast cancer cells. Anticancer Res 30: 3381-3390, 2010.

28. Liu D, Yang Y, Liu Q and Wang J: Inhibition of autophagy by 3-MA potentiates cisplatin-induced apoptosis in esophageal squamous cell carcinoma cells. Med Oncol 28: 105-111, 2011. 